\title{
Diverse HTS Hysteresis Motors
}

\author{
Sandipan Paul, Joyashree Das
}

\begin{abstract}
The comparative study of HTS hysteresis motor with $Y B C O$ and BSCCO element in the rotor and copper conductors in the stator is proposed in this paper. Both the elements are used as rotor materials. Then the effect of each material is numerically calculated and simulated using AV formulation. Various performance parameters such as magnetic flux density, magnetic field and current density etc. of hysteresis motor and hysteresis rotor with both materials are computed. For this, two dimensional Partial Difference Equation based module of COMSOL Multiphysics has been used with two dimensional geometry with proper Neumann and Dirichlet boundary conditions. COMSOLA Multiphysics is finite element based solver software. The computed constraints are evaluated with each other.
\end{abstract}

Keywords- High Temperature Superconducting (HTS), Hysteresis Motors, Bismuth Strontium Calcium Copper Oxide (BSCCO), Yttrium Barium Copper Oxide (YBCO) Finite Element Method.

\section{INTRODUCTION}

In recent times, Hysteresis motors with HTS materials have involved further attraction due to its exclusive advantages. Compared with the conventional hysteresis motors of same power, it has the advantages of compact size, low weight, quite operation, high power density and being less expensive to operate because of their high magnetization and magnetic field etc. It has the capability to produce a constant torque during running condition and also operates in a steady speed without depending on the other torques [1]. Due to such special properties, hysteresis motor particularly suitable for different fractional horse power application such as ATM, air conditioner, entry verification, audio systems etc. Although the conventional hysteresis motor has various restrictions. To overcome such limitations and to get better output of the performance of hysteresis motor, several techniques are available. Among these techniques, changing of magnetic material is one the technique for the performance improvement of such motors. The use of Superconducting materials in the rotor of hysteresis motors have been discovered by the researchers [2], as these materials are capable to carry huge amount of magnetic field as compared to conventional hysteresis motor. Nowadays, these types of motors provide higher output efficiency, greater current density and better power output etc. [3]-[32].

In this paper, rotor of hysteresis motor using different types of HTS elements is presented. Then the various performance parameters are calculated in MATLAB and

Revised Manuscript Received on December 16, 2019

Sandipan Paul, Department of Electrical Engineering, National Institute of Technology Agartala, Jirania, Tripura (west), Pin:-799046, India.

Joyashree Das, Department of Electrical Engineering, National Institute of Technology Agartala, Jirania, nTripura (west), Pin:-799046, India.
COMSOL Multiphysics software and finally measured parameters are compared.

This paper consists of three sections. In section 2, the proposed structure of hysteresis motor is developed. Then the simulation and experimental results are shown in Section 3, and lastly in Section 4, conclusions can be drawn.

\section{MODELING OF HYSTERESIS MOTOR}

\section{Proposed Structure of HTS Hysteresis Motor}

The proposed structure of hysteresis motors with YBCO and BSCCO elements in the rotor are shown in Fig. 1. This motor is consisting of conventional copper conductors in the stator slots. The rotor core is accumulated with paramagnetic materials. For the purpose of mechanical sustain of rotor material. The shaft is made up with steel. Due to the presence of paramagnetic materials between them, the distribution of flux increases with the increase of numbers of the circular sectors. But it must be restricted; otherwise flux leakage will be higher and correspondingly torque decreases [5].

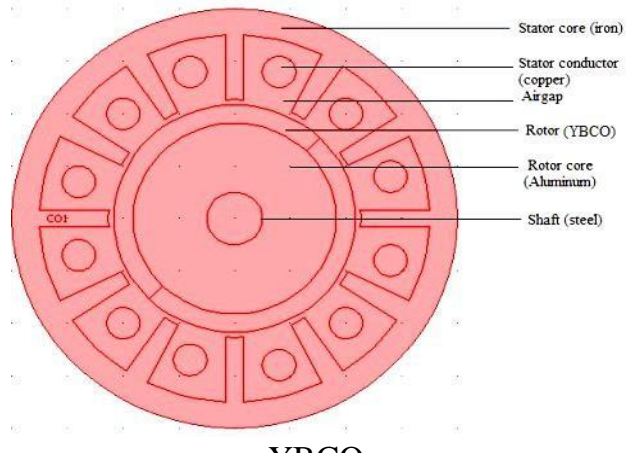

a. $\mathrm{YBCO}$

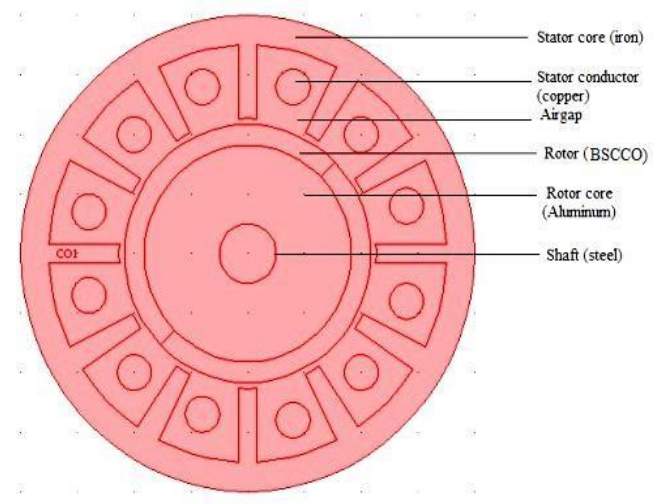

b. BSCCO

Fig. 1. Schematic diagram of hysteresis motors with ybco and bscco materials in comsol multiphysics. 


\section{Diverse HTS Hysteresis Motors}

\section{SIMULATION AND EXPERIMENTAL RESULTS}

The dynamic expression of the motor is

$\nabla \times\left(\mu_{0}{ }^{-1} \mu_{r}^{-1}\left(\nabla \times A_{z}-B_{r}\right)-\sigma v \times \nabla \times A_{z}\right)-\left(\sigma \Delta V / L+J_{z}{ }^{e}\right) A_{z}=0$

Where, $\mu$ is permeability $(H / m), \sigma$ is conductivity $(S / m), J_{z z} e^{e}$ is external current density $\left(A / \mathrm{m}^{2}\right), V$ is velocity $(\mathrm{m} / \mathrm{s}), A_{z}$ is magnetic potential $(\mathrm{Wb} / \mathrm{m})$,

$B_{r}$ is residual flux density $(T)$ and $A_{r}$ is area of the rotor respectively. The details of the HTS materials used in the rotor are described in Table I and Table II.

Table I. Details of the HTS material used in the rotor.

\begin{tabular}{|c|c|}
\hline Name of the sample & YBCO $/$ BSCCO \\
\hline Outer radius $(m)$ & 0.024 \\
\hline Inner radius $(m)$ & 0.01 \\
\hline Thickness $(m)$ & 0.003 \\
\hline Critical electric field $(V / m)$ & $10^{-4}$ \\
\hline External current density $\left(\mathrm{A} / \mathrm{m}^{2}\right)$ & $100 / \mathrm{Ar}$ \\
\hline
\end{tabular}

Table II. Details of conventional and HTS hysteresis motor.

\begin{tabular}{|c|c|c|}
\hline Dimensions & $\begin{array}{c}\text { Conventional } \\
\text { hysteresis motor } \\
(\mathrm{m})\end{array}$ & $\begin{array}{c}\text { HTS } \\
\text { hysteresis motor } \\
(\mathrm{m})\end{array}$ \\
\hline Outer radius of stator & 0.06 & 0.04 \\
\hline Outer radius of rotor & 0.028 & 0.024 \\
\hline Inner radius of rotor & 0.026 & 0.01 \\
\hline Length of air-gap & 0.001 & 0.001 \\
\hline
\end{tabular}

The mesh statistics are used in both the HTS elements to split the motor into small limited elements. Higher nodes are produced in hysteresis rotor compared to other regions. Various parameters are known from this mesh statistics, which is shown in Table III.

Table III. Mesh statistics of hysteresis motors with YBCO and BSCCO materials

\begin{tabular}{|c|c|c|}
\hline Mesh statistics & YBCO & BSCCO \\
\hline Mesh & Triangular & Triangular \\
\hline Number of elements & 23604 & 14622 \\
\hline $\begin{array}{c}\text { Number of boundary } \\
\text { elements }\end{array}$ & 1558 & 1234 \\
\hline $\begin{array}{c}\text { Number of degrees of } \\
\text { freedom }\end{array}$ & 47110 & 29106 \\
\hline Number of vortex elements & 180 & 180 \\
\hline Number of mesh point & 11887 & 7355 \\
\hline Solution time $(s)$ & 19.176 & 7.846 \\
\hline
\end{tabular}

The solution time depends on input parameters but others parameters will remain similar unless the geometry is reformed. The mesh diagrams of both HTS hysteresis motor with YBCO \& BSCCO element in the rotor are shown in Fig. 2.


b. BSCCO

Fig. 2. Mesh diagram of both hysteresis motors.

\section{A. Effect of Distribution of Flux in both HTS Hysteresis Motor}

The magnetic flux density, magnetic potential and magnetic field plot in a HTS hysteresis motor with YBCO \& BSCCO elements are shown in Fig.3, Fig. 4 and Fig. 5. From Fig. 5 to Fig.8, It can be noticed that a magnetic field of two poles is produced in both HTS hysteresis motor. The revolving stator flux produces currents in the rotor and thus the rotor is magnetized. Huge amount of magnetic fluxes are ambushed in the rotor with superconducting element, which is shown in all the figures from Fig. 3 to Fig. 5. From the figures, it is observed that more fluxes are trapped in BSCCO material than the YBCO material. Therefore the value of magnetic flux density, magnetic potential and magnetic field are higher in BSCCO element than the YBCO element. 

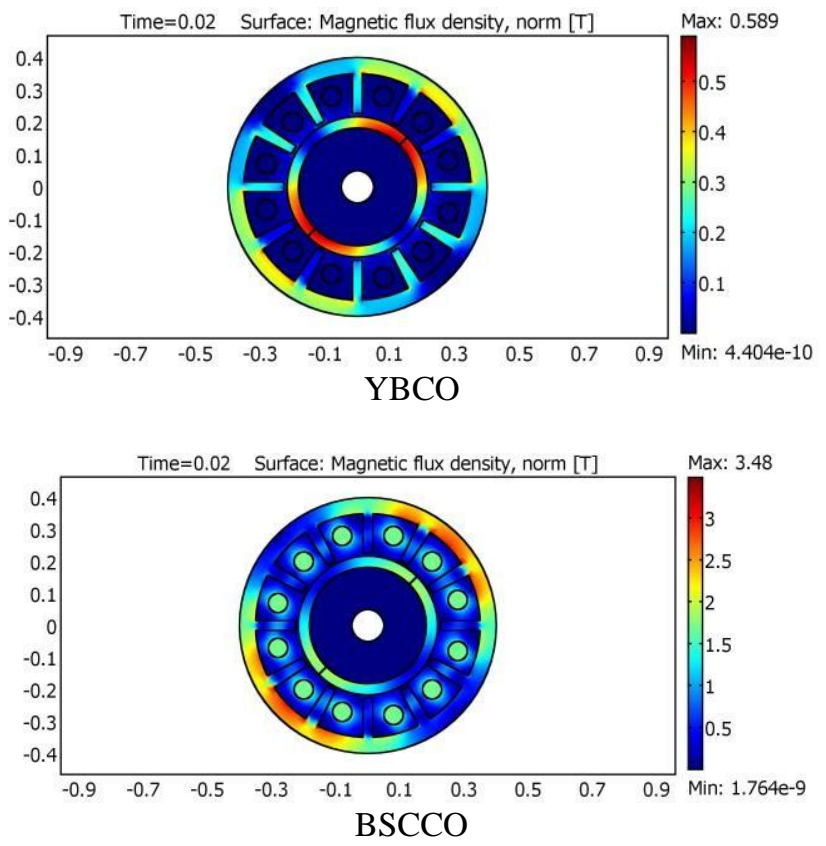

Fig. 3. The surface plot of magnetic flux density $(B)$ in hysteresis motor with YBCO and BSCCO.

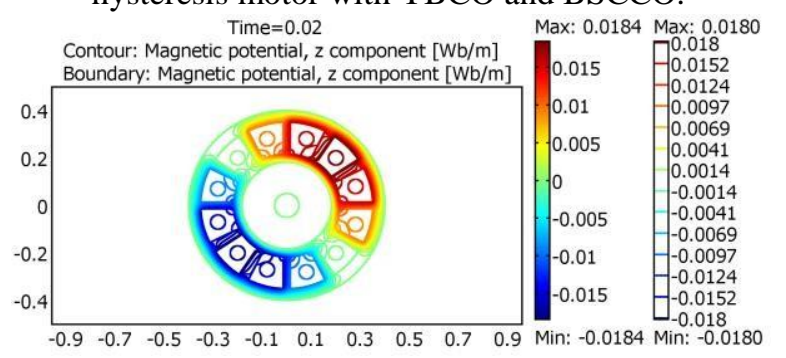
$\mathrm{YBCO}$

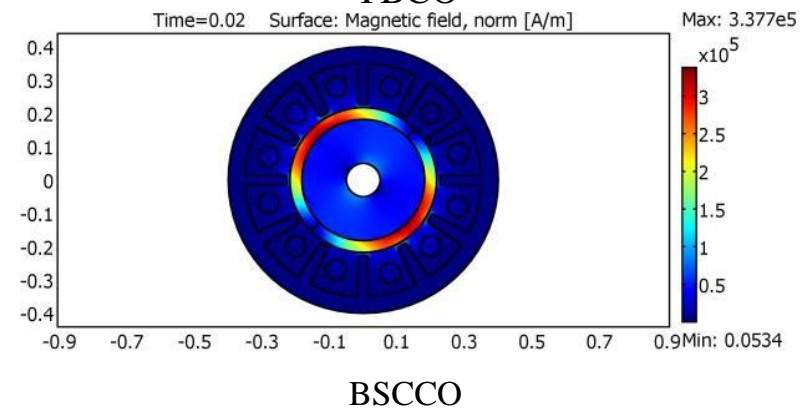

Fig. 4. Contour and Boundary plot of magnetic potential in hysteresis motor with YBCO and BSCCO.



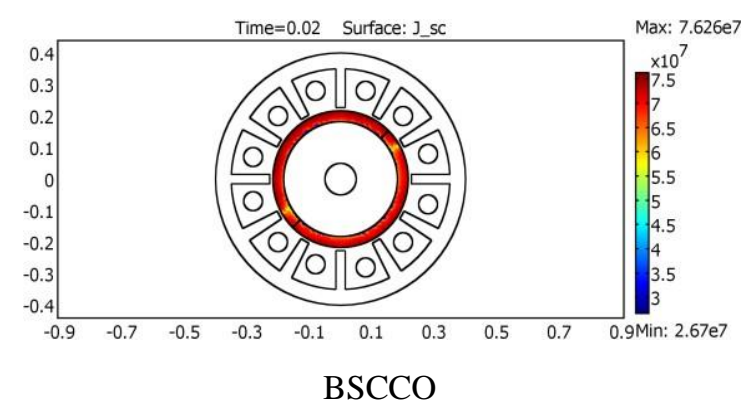

Fig. 5. Magnetic field $(H)$ plot in hysteresis motor with YBCO and BSCCO.

B. Effect of Current Density in a Hysteresis Motor with HTS Elements

The current density plots of HTS hysteresis rotor with both materials are shown in Fig. 6. Due to high current carrying property of superconducting materials, the current density is more in that region. But it is not uniform due to the anisotropic property of HTS material. When the reduction of trapped fields inside the HTS rotor, the current density decreases with minimum value in the internal section of the rotor. The value of integral of current density in HTS rotor in YBCO material and BSCCO material are $7.156469 * 10^{6} \mathrm{~A} / \mathrm{m}^{2}$ and $1.502725 * 10^{6} \mathrm{~A} / \mathrm{m}^{2}$, which is smaller amount compared to the critical current density $\left(5^{*} 10^{8} \mathrm{~A} / \mathrm{m}^{2}\right)$ for the same value of power index $(n)$ i.e. 21 and the value of integral of current density in BSCCO material is higher than the YBCO material.
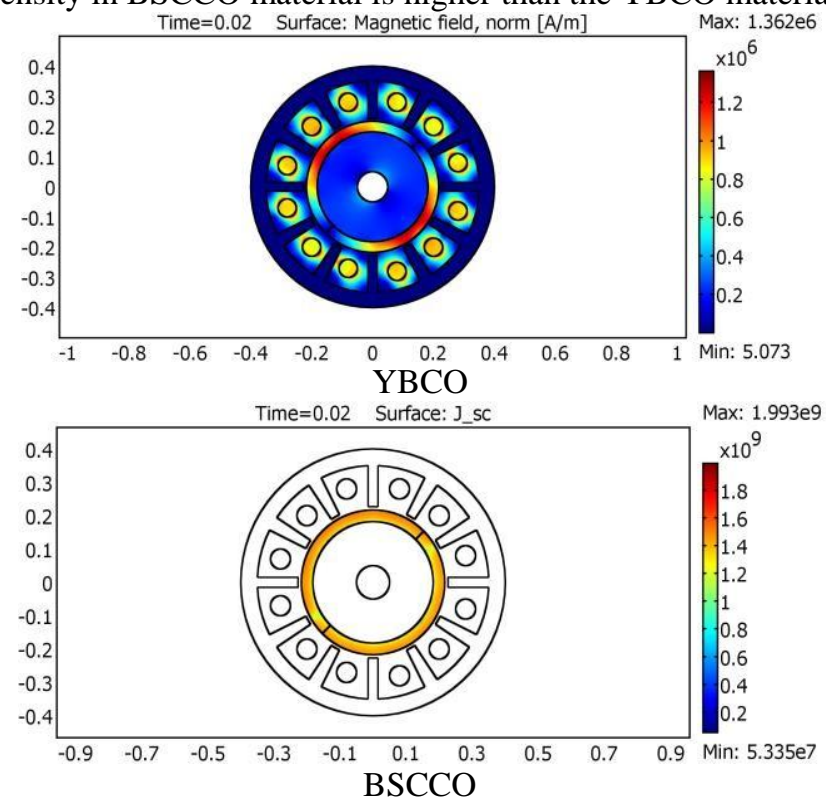

Fig. 6. Current density plot in hysteresis rotor with YBCO and BSCCO.

\section{CONCLUSION}

In this paper, comparative study of hysteresis motor with BSCCO and YBCO elements in rotor is presented and calculated in MATLAB and COMSOL Multiphysics software. Simulated results show that BSCCO material has the ability to carry large amount of magnetic field, magnetic flux density and current density compared to

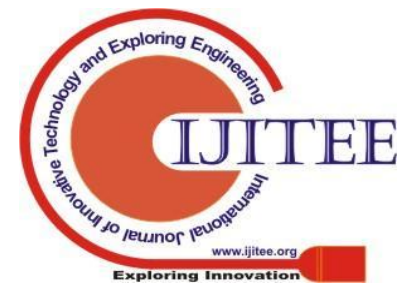




\section{Diverse HTS Hysteresis Motors}

YBCO material. The hysteresis motor with BSCCO material in the rotor gives superior results compared to $\mathrm{YBCO}$ material.

\section{ACKNOWLEDGMENTS}

The author's special thanks to the COMSOL Multiphysics group for arranging workshop which was very helpful for the work.

\section{REFERENCES}

1. Das J. \& Ray R.N.: Design and Modeling of Hysteresis Motor with High Temperature Superconducting Material in the Rotor using Finite Element Method. Innovative Systems Design and Engineering, Vol.3No.6, (2012) 68-76.

2. Barnes, G. J., McCulloch, M. D., \& Dew-Hughes, D. :Torque from hysteresis machines with type-II superconducting segmented rotors. Physica C: Superconductivity, 331(2), (2000) 133-140.

3. Das J. \& Ray R.N. :Comparison of 2D and 3D Modeling of Hysteresis Motor with HTS Element in the Rotor", International Journal of Engineering Research and Applications, vol. 2, Issue 5, (2012).

4. Inacio, D., Inacio S., Pina, J., Goncalves, A., Ventim, Neves, M., \& Rodrigues, Leao, A. : Numerical and experimental comparison of electromechanical properties and efficiency of HTS and ferromagnetic hysteresis motors. $8^{\text {th }}$ European Conference On Applied Superconductivity (EUCAS 2007), (2007) 1-7.

5. Rodrigues, Leao, A.: Drum and disc type hysteresis machines with superconducting rotors. IEEE, (2009) 55-59.

6. Chari, M. V. K., and Silvester, P. P.: Finite Elements in Electrical and Magnetic Field Problems. New York: John Willy and Sons, (1980) 3136.

7. Das J. \& Ray R.N.: Studies on hunting of Hysteresis motor with HTS element on rotor" IEEE First International Conference on Power Electronics, Intelligent Control and Energy System, (2016) 4-6 July,2016, Delhi.

8. Hong-Kyu, Kim, Sun-Ki, Hong, \& Hyun-Kyo, J.: Analysis of hysteresis motor using finite element method and magnetization- dependent model. IEEE Transactions On Magnetics, 36(4), (2000) 685-688.

9. Sun-Ki, Hong, Hong-Kyu, Kim, Hyeong-Seok, Kim, \& Hyun-Kyo, J.: Torque calculation of hysteresis motor using vector hysteresis model. IEEE Transactions On Magnetics, 36(4), (2000) 1932- 1935.

10. Lee, Hak-Yong, Hahn, Song-yop, Park, Gwan-Soo, \& Lee, Ki-Sik.

11. :Torque computation of hysteresis motor using finite element analysis with asymmetric two dimensional magnetic permeability tensor. IEEE Transactions On Magnetics, 34(5), (1998) 3032-

12. 3035 .

13. Sadeghi, H., M., \& Darabi, A.: Optimization of a new type of hysteresis motor using genetic algorithm. EEEIC, (2010) 479-482.

14. Kubota, T., Tamura, T., \& Kurihara, K. : High-efficiency operation of PWM inverter-driven hysteresis motor with short-duration overexcitation. Proc. Int. Conf. Elect. Mach. And Systems, (2009) 1-4.

15. Kubota, T., Tamura, T., \& Kurihara, K. : New scheme for highefficiency operation of PWM inverter-driven hysteresis motor with short-duration overexcitation. International Conference on Electrical Machines, (2010) 1-6.

16. Kubota, T., Tamura, T., \& Kurihara, K.:Characteristics of PWM inverter-driven hysteresis motor with short-duration overexcitation. ICEMS, (2010) 1429-1433.

17. Kovalev, L., K., Ilyushin, K., V., Penkin, V., T., \& Kovalev, K., L.: Hysteresis machines with high temperature superconducting rotors. Elsevier Science, (1994) 145-170.

18. Habisreuther, T., Strasser, T., Gawalek, W., Goornert P., Ilushin, K., V., \& Kovalev, L., K.: Magnetic processes in hysteresis motors equipped with melt-textured YBCO. IEEE Transactions On Applied Superconductivity, 7(2), (1997) 900-903.

19. Kovalev, L., K., Ilushin, K., V., Koneev, S., M., A., Kovalev, K., L., Penkin, V., T., Poltavets, V., N., Gawalek, W., Habisreuther, T., Oswald, B., \& Best, K., J.: Hysteresis and reluctance electric machines with bulk HTS rotor elements. IEEE Transactions On Applied Superconductivity, 9(2), (1999) 1261-1264.

20. Kovalev, L., K., Ilushin, K., V., Kovalev, K., L., Penkin, V., T.,
Poltavets, V., N., Gawalek, W., \& Habisreuther, T. et al.: Hysteresis electrical motors with bulk melt texture YBCO. Material Science and Engineering, (1998) 216-219.

21. Kovalev, L., K., Ilushin, K., V., Koneev, S., M., A., Kovalev, K., L., Penkin, V., T., Modestov, A., K., Larionoff, A., S., Gawalek, W., \& Oswald, B.: HTS electrical machines with YBCO bulk and Ag-BSCCO plate-shape HTS elements: recent results and future development. Physica C: Superconductivity, 354(1-4), (2001) 34- 39.

22. Oswald, B., Krone, M., Strasser, T., Best, K., J., \& Soil, M. et al.: Design of HTS reluctance motors up to several hundred kW. Physica C: Superconductivity, 372-376 (2), (2002) 1513-1516.

23. Muta, I., Jung, H., Nakamura, T., \& Hoshino, T.: Performance of axialtype motor with Bi-2223 HTS bulk rotor. Physica C: Superconductivity, 372-376(3), (2002) 1531-1534.

24. Wakui, G., Kurihara, K., \& Kubota, T.: Radial flux type hysteresis motor with rotor ring of sprayed surface layer. Electrical Engineering in Japan, 112(4), (2007) 132-143.

25. Match, L., \& Morgan, J.: Electromagnetic and Electromechanical Machines. Wiley \& Sons (1986).

26. McCulloch, M., \& Dew-Hughes, D. :Brushless ac machines with high temperature superconducting rotors. Material Science and Engineering B53, (1998) 211-215.

27. Chun, Y. D., Kim, Y. H., Lee, J., Hong, J. P., \& Lee, J. W.: Finite element analysis of magnetic field in high temperature bulk superconductor. IEEE Trans. On Applied Superconductivity 11(1), 11(2), (2001) 2000-2003.

28. Suguira, T., Shashizume, H., and Mika, K.: Numerical electromagnetic field analysis of type II superconductors. Int J. of Applied Electromagnetics in Materials 2, (1991) 183.

29. Nakamura, T. et al.: Synchronization of an axial type Bi2223 bulk motor operated in liquid nitrogen. Superconductor Science and Technology 17, (2004) 1319-1323.

30. Das J. \& Ray R.N. 3D modeling of high temperature superconducting hysteresis motor using COMSOL Multiphysics. 2017, $8^{\text {th }}$ Annual Industrial Automation and Electromechanical Engineering Conference (IEMECON), 16-18 ${ }^{\text {th }}$ August 2017, Bangkok, Thailand.

31. G. Konar, N. Chakrabortya, J. Das. : Performance Calculation of High Temperature Superconducting Hysteresis Motor. Physics Procedia, Elsevier, vol. 36, (2012) 963-968.

32. Stephen L. Herman : Electrical Transformers and Rotating Machines. (2011) .

33. Bin Liu, Rod Badcock, Hang Shu \& Jin Fang : A Superconducting Induction Motor with a High Temperature Superconducting Armature: Electromagnetic Theory, Design and Analysis. Energies 2018, 11(4), 792.

34. Bin Liu, Jin Fang, Junci Cao, Jie Chen, Hang Shu and Long Sheng : Electromagnetic Performance Calculation of HTS Linear Induction Motor for Rail Systems. IOP Conference Series: Journal of Physics: Conf. Series 871 (2017).

\section{AUTHORS PROFILE}



Dr. Joyashree Das, Manjula L Working as Assistant Professor at NIT Agartala. She has completed B.Tech (NIT Agartala), ME (JU), Ph.D (NIT Agartala).Her Areas of Interest includes Basic Electrical Technology, Power Systems and Superconductivity. 